Fetal Diagnosis and Therapy
Fetal Diagn Ther 2015;37:6-17

DOI: $10.1159 / 000362663$
Received: May 11, 2013

Accepted after revision: March 30, 2014

Published online: November 11, 2014

\title{
Neural Tube Defects: The Experience of the Registry of Congenital Malformations of Alsace, France, 1995-2009
}

\author{
Dana Timbolschi $^{\mathrm{a}}$ Elise Schaefer ${ }^{\mathrm{a}} \mathrm{h}$ Bondo Monga ${ }^{\mathrm{h}}$ Delphine Fattori ${ }^{\mathrm{h}}$ \\ Béatrice Dott $^{\mathrm{a}} \quad$ Romain Favre $^{\mathrm{b}}$ Monique Kohler ${ }^{\mathrm{b}}$ Israël Nisand ${ }^{\mathrm{c}}$ \\ Brigitte Viville $^{c}$ Dominique Astruc ${ }^{d}$ Pierre Kehrlie Bernard Gasser ${ }^{i}$ \\ Véronique Lindner ${ }^{i} \quad$ Luc Marcellin $^{f}$ Elisabeth Florig ${ }^{9}$ Françoise Girard-Lemaire ${ }^{g}$ \\ Hélène Dollfus ${ }^{a, h}$ Bérénice Doray ${ }^{a, h, j}$

\begin{abstract}
a Service de Génétique Médicale, ${ }^{b}$ Service de Gynécologie-Obstétrique, CMCO-SIHCUS, 'Département de Gynécologie-Obstétrique, Hôpital de Hautepierre, ' Service de Pédiatrie II, 'Service de Neurochirurgie,

${ }^{f}$ Service d'Anatomie Pathologique and ${ }^{9}$ Service de Cytogénétique, Hôpitaux Universitaires de Strasbourg, and

h'Laboratoire de Génétique Médicale INSERM U1112, Faculté de Médecine, Université de Strasbourg, Strasbourg,

'Service d'Anatomie Pathologique, Centre Hospitalier Général de Mulhouse, Mulhouse, and 'Service de Génétique -
\end{abstract} \\ CHU La Réunion, Hôpital Félix Guyon, Saint-Denis, France
}

\section{Key Words}

Neural tube defects · Epidemiology · Genetics ·

Prenatal diagnosis

\begin{abstract}
Context and Objective: Considering the lack of accurate and up-to-date information available about neural tube defects (NTDs) in France, the purpose of this study was to review clinical and epidemiological data of NTDs and to evaluate the current efficiency of prenatal diagnosis in Alsace (northeastern France). Methods: A population-based retrospective study was performed from data of the Registry of Congenital Malformations of Alsace between 1995 and 2009. Data were analyzed as a whole and according to the anatomical type of the malformation (anencephaly, cephalocele and spina bifida). Statistical analyses were carried out using the Statistical Package for the Social Sciences. Results: 272 NTDs were
\end{abstract}

recorded divided in 113 cases of anencephaly (42\%), 35 cases of cephalocele (13\%) and 124 cases of spina bifida (45\%). The total prevalence at birth of $14 / 10,000$ (95\% Cl 13-16) was stable throughout the reporting period. A chromosome abnormality was identified in 27 cases (12\% of all karyotyped cases). NTDs were prenatally diagnosed by ultrasound in $88 \%$ of the cases. The mean age upon prenatal diagnosis slightly declined during the 15-year period, significantly for spina bifida only. The global rate of terminations of pregnancy following prenatal diagnosis was 97\% (230/238). Conclusion: This work constitutes a unique population-based study providing accurate and specific up-to-date data from a unique center over a longer period (1995-2009). The most important information concerns the high and stable prevalence, which calls into question the efficiency of the primary prevention by folic acid supplementation and the efficiency of prenatal diagnosis.

(c) 2014 S. Karger AG, Basel

\section{KARGER 125}

(c) 2014 S. Karger AG, Base

$1015-3837 / 14 / 0371-0006 \$ 39.50 / 0$ 


\section{Introduction}

Neural tube defects (NTDs) are a frequent group of severe anomalies of the central nervous system. Commonly included in this group are anencephaly, spina bifida and cephalocele $[1,2]$. NTDs arising as a result of a primary failure of the neural tube closure between the 17th and 30th postfertilization days are clinically apparent by being open, in contrast to postneurulation NTDs, which are skin-covered-like cephaloceles $[1,2]$.

The development of the neural tube is a multistep process strictly controlled by genes and modulated by a host of environmental factors [3]. The etiology of NTDs remains poorly understood; if some are due to chromosomal anomalies or monogenic syndromes, it is generally agreed that most of them have a multifactorial origin, with a significant genetic component interacting with environmental risk factors $[4,5]$. NTDs are one of the few congenital anomalies relevant to primary prevention with folic acid supplementation or fortification $[6,7]$. Significant progress has been made over the past 20 years in fetal medicine and prenatal diagnosis and nowadays the majority of NTDs are prenatally diagnosed [8-11].

The aim of this study was to analyze between 1995 and 2009 the following information about NTDs: epidemiological data, anatomical type, frequency and type of associated malformations, frequency and type of chromosomal anomalies or monogenic syndromes, circumstances of prenatal diagnosis (gestational age, prenatal ultrasound data) and evolution of the rate of prenatal diagnosis, and outcome of pregnancy. Previous studies have been undertaken about NTDs, some of them reporting data issued from French registries of congenital malformations (including ours). Nevertheless, these data were aggregated across the different centers and did not provide detailed and specific results concerning the evolution of French prenatal diagnosis over time [8-12]. This study is the first one to present a large French cohort of NTDs over a longer and recent period of time (19952009).

\section{Patients and Methods}

Registry of Congenital Malformations of Alsace, France

The Registry of Congenital Malformations of Alsace is the only population-based registry of northeastern France. The population covered includes infants born to mothers living and giving birth in the Départements of Bas-Rhin and Haut-Rhin of the Alsace region. The overall population is about $1,800,000$ inhabitants with an average number of 23,000 births per year (corresponding to ap- proximately 3\% of all births in France). The denominators for the population of the registry are provided by the National Institute of Statistics and Economic Studies (INSEE). The registry focuses on congenital malformations and/or chromosomal anomalies among live births (anomaly detected during the pregnancy or after birth up to the 24th month of life of the child), stillbirths after 20 weeks' gestation only and terminations of pregnancy (ToPs) whatever the gestational age. The ascertainment of cases is actively carried out from multiple sources of information to improve the completeness and the quality of data. The Registry of congenital Malformations of Alsace is a member of the EUROCAT network (www.eurocatnetwork.eu) [13] and of the International Clearinghouse for Birth Defects Surveillance and Research (www.icbdsr.org).

Study Population, Inclusion Criteria and Data Analyzed

This study concerned cases with NTDs whose mothers lived and gave birth in the department of Bas-Rhin between January 1995 and December 2009. During this 15-year period, a total of 192,391 births were registered.

NTDs were defined according to well-established pathological criteria into the following three subgroups: (1) anencephaly/exencephaly, defined as an absent calvarium with total or partial absence of the brain and including cases of craniorachischisis; (2) cephalocele, defined as a herniation of meninges (meningocele) and/or brain tissue (meningoencephalocele) through a defect in the calvarium, and (3) spina bifida, defined as a bony defect of the spine with exposure of meninges and/or neural tissue, and encompassing several subgroups of defects, the most serious of them being myelomeningocele. As NTDs may be difficult to classify, every case was reviewed by B.D. and amended if necessary. One case of anencephaly (prenatally diagnosed) associated with a small lumbar spina bifida occulta (diagnosed at autopsy) was classified into the group anencephaly considering that the diagnosis and the outcome of pregnancy were related only to the presence of anencephaly.

Data were obtained from multiple sources including obstetrical and ultrasound reports, pediatric and child surgery units, health certificates, reports from medical genetic units, reports from cytogenetics and fetopathological laboratories. Autopsies were performed by three practitioners (B.G., V.L., L.M.) working in two nearby hospitals and all of these consisted in external and internal examination and $\mathrm{x}$-rays in a standardized way.

The following data were analyzed: epidemiological data, anatomical type of the malformation, frequency and type of associated malformations, frequency and type of chromosomal anomalies or monogenic syndromes, circumstances of prenatal diagnosis (gestational age, prenatal ultrasound data) and evolution of the rate of prenatal diagnosis and outcome of the pregnancy. All NTDs were included among live births (anomaly detected during the pregnancy or after birth up to the 24th month of life), stillbirths after 22 weeks of amenorrhea (WA) and ToPs (whatever the term of pregnancy). Stillbirths with NTDs before 22 spontaneous abortions (SA) were not included as recommended by EUROCAT.

The term 'total prevalence at birth' was used as the number of NTD-affected pregnancies resulting in ToPs (for fetal anomaly), stillbirths after $22 \mathrm{WA}$ and live births per 10,000 ToPs, stillbirths and live births; the term 'birth prevalence' was the number of stillbirths after 22 WA and live births with a NTD per 10,000 stillbirths and live births. Stillbirths before 22 SA are not recorded by INSEE. 
Fig. 1. 15-year prevalence (in box text) and prevalence by 5 -year periods of delivery of NTDs. The prevalences by 5 -year periods are indicated per 10,000 births (live births and stillbirths) and ToPs. The term prevalence corresponds to total prevalence at birth.

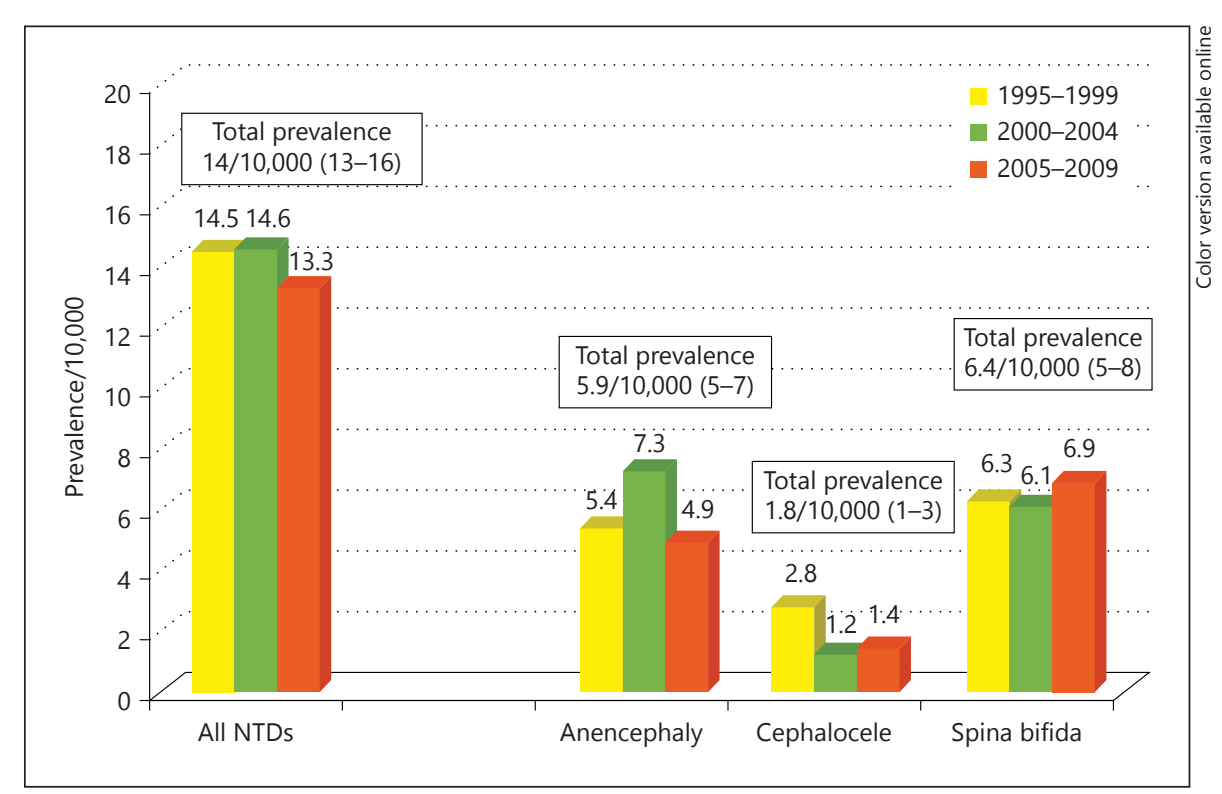

In France, three systematic fetal ultrasounds are recommended, but not mandatory. The first one during the first trimester (between 11 and $14 \mathrm{WA}$ ) is useful to date the pregnancy, to identify and characterize multiple pregnancies and to screen some malformations and the risk of chromosomal abnormalities; the objectives of the second one (between 20 and $25 \mathrm{WA}$ ) are to diagnose some defects, and the third one (between 30 and 35 SA) is used to identify fetal growth restriction and malformations, location of the placenta and fetal presentation.

In this study, all cases had at least one fetal ultrasound. 65\% $(177 / 272)$ of pregnant women had more than five fetal ultrasounds, $18 \%$ (49/272) had five, $12 \%(32 / 272)$ had four, $4 \%(11 / 272)$ had three, and $1 \%(3 / 272)$ had only one.

\section{Statistical Analysis}

Descriptive analysis was carried out using the Statistical Package for the Social Sciences. Confidence intervals were calculated using the Confidence Interval Analysis package. The $\chi^{2}$ test for trend was used to compare differences in total prevalence at births and birth prevalence over time, and the $\chi^{2}$ test was applied to test for differences in proportions. Statistical significance was accepted at the $\mathrm{p}<0.05$ level.

\section{Results}

\section{Prevalence and Distribution of Neural Tube Defects}

(fig. 1)

272 cases were collected during the 15 -year period, divided in 113 cases (41\%) of anencephaly (including 18 craniorachischisis), 35 cases (13\%) of cephalocele, and 124 cases $(46 \%)$ of spina bifida. The total prevalence at birth of all NTDs was 14/10,000 (binomial exact method; 95\% CI 13-16).
The total prevalence at birth for all NTDs was quite stable during the first decade of the study $(14.5 / 10,000$ [12-18] between 1995 and 1999 and 14.6/10,000 [12-18] between 2000 and 2004) and was slightly lower (13.3/10,000 [11-16]) between 2005 and 2009 but this decrease was not statistically significant ( $\chi^{2}$ test, $\mathrm{p}=0.77$ ). The prevalence variations of each NTD over time were not statistically significant $\left(\chi^{2}\right.$ tests, $p=0.065, p=0.17$ and $\mathrm{p}=0.81$ for anencephaly, cephalocele and spina bifida, respectively) (fig. 1).

\section{Sex Ratio, Parental Age, Recurrence, Fertilization,}

\section{Consanguinity, and Twins}

These data have been detailed in table 1 .

- There was an excess of female cases for each NTD with sex ratio of $0.9(53 / 59)$ for anencephaly, $0.7(14 / 21)$ for cephalocele, and 0.8 (55/69) for spina bifida.

- The average parental (maternal and paternal) age was the lowest for anencephaly (27.6 and 31.4, respectively) and the highest for spina bifida (29.9 and 33.3).

- If consanguinity was rarely reported in anencephaly $(2 / 113 ; 1.8 \%)$ and spina bifida $(3 / 124 ; 2.4 \%)$ it was more frequently associated with cephalocele (4/35; $11.4 \%)$.

- Intrafamilial recurrence concerned about 5\% of cases with isolated anencephaly and 5\% of cases with isolated spina bifida. It was not common for cephalocele and concerned only a case with Meckel syndrome within a large consanguineous family. 
Table 1. Sex ratio, type of fertilization, consanguinity, twin pregnancy and familial recurrence for each type of NTD

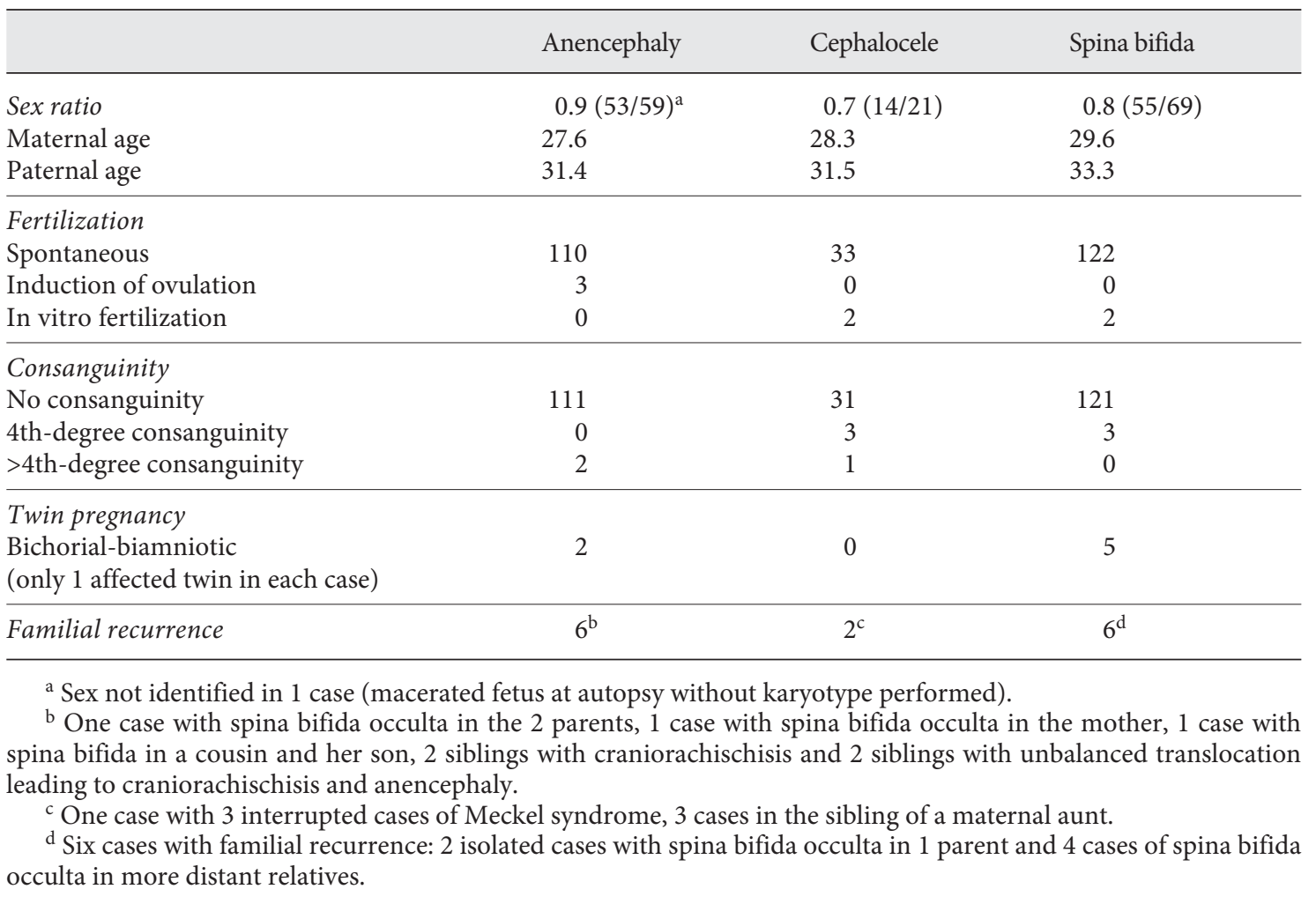

- Twin pregnancies (all bichorial-biamniotic) were more frequently reported in the group of spina bifida ( 5 vs. 2 cases in the group of anencephaly and none in the group of cephalocele).

\section{Anatomical Types}

- Anencephaly: This group was divided in two subtypes anencephaly $(95 / 113 ; 84 \%)$ and craniorachischisis $(18 / 113 ; 16 \%)$. Among craniorachischisis, 15 were cervical, 1 cervicothoracic, 1 cervicothoracolumbar, and 1 cervicothoracolumbosacral.

- Cephalocele: This group was composed of 22 cases of encephalocele and 13 cases of meningocele (37\%). Among the 22 encephaloceles, 4 were anterior (18\%) and 18 posterior (82\%). All meningoceles had posterior localization.

- Spina bifida: The majority had thoracolumbar $(14 / 124 ; 11 \%)$, lumbar $(43 / 124 ; 35 \%)$ or lumbosacral (56/124; 45\%) levels; the others had cervical (1 case), cervicothoracic (1 case), thoracic (1 case), sacral (6 cases) and thoracolumbosacral (2 cases) localizations.
Associated Malformations and Syndromes

- Anencephaly (fig. 2): Anencephaly was isolated in 87 cases (77\%). Among the 92 karyotyped cases (81\%), 9 chromosome anomalies were identified (10\%) including 4 cases of trisomy 18. Apart from chromosomal abnormalities, 8 cases of amniotic bands sequence and 4 cases of complex celosomies were recorded. In 5 cases, associated anomalies were present but a specific syndrome could not be recognized.

- Cephalocele (fig. 3): A karyotype was performed in 30 cases $(86 \%)$ and no chromosome abnormality was recorded. Associated malformations were reported in 22 out of the 35 cases (63\%): 50\% (2/4) of associated anterior encephaloceles were associated, versus 59\% $(10 / 17)$ of posterior encephalocele, and $71 \%(10 / 14)$ of posterior meningoceles. Monogenic syndromes were reported in 8 cases, including 6 cases of Meckel syndromes all issued from consanguineous unions. In 11 cases, associated anomalies were present but no specific syndrome was recognized.

- Spina bifida (fig. 4): A karyotype was performed in 100 cases (81\%). 18 chromosome anomalies were identified 


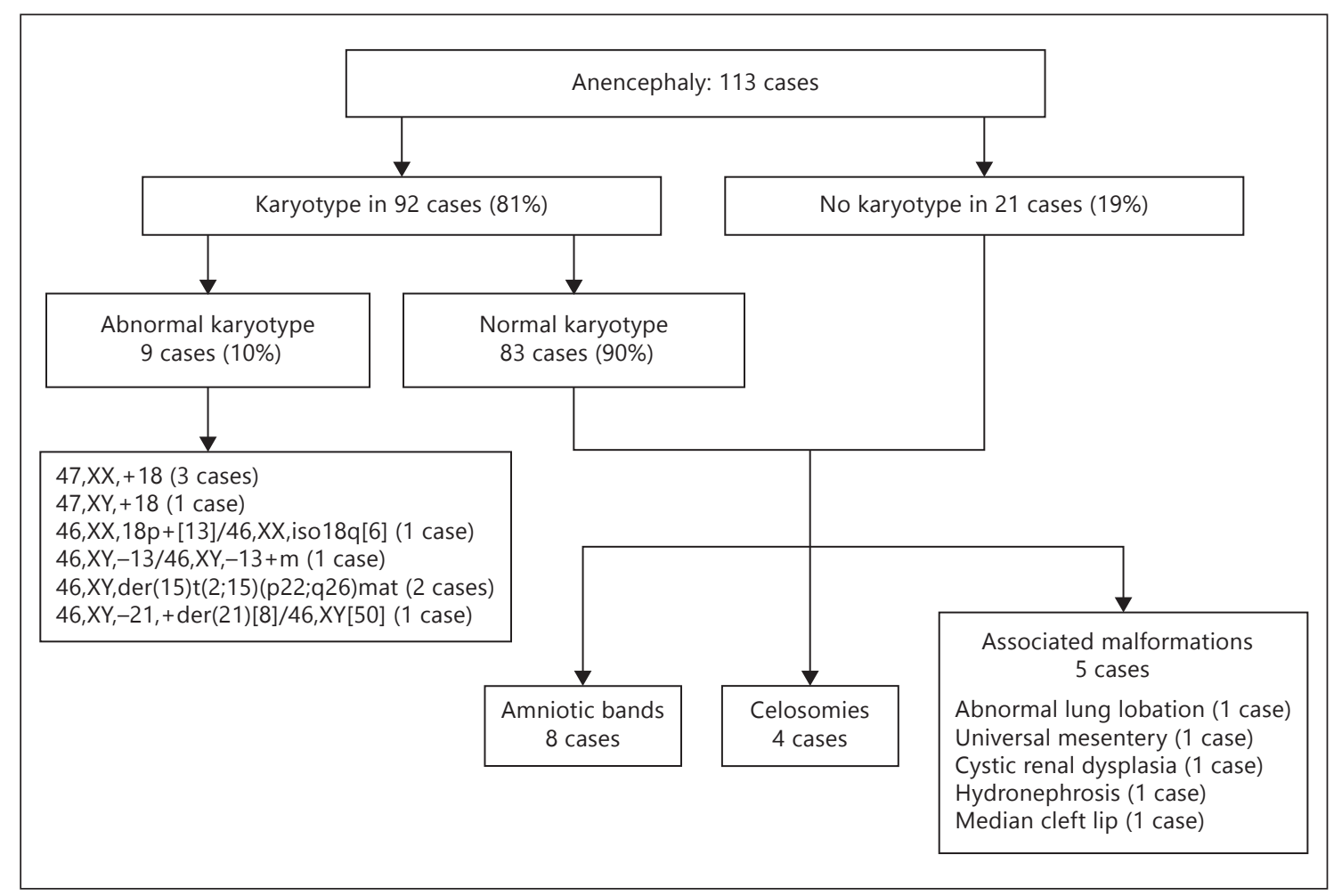

Fig. 2. Distribution and description of isolated and associated (syndromic or non-syndromic) cases with anencephaly.

among the karyotyped cases (18\%) including 11 cases of trisomy 18. Apart from chromosomal abnormalities, 1 case of amniotic bands sequence, 1 case of caudal regression sequence, and 2 cases of celosomy were present. Other malformations were identified in 28 cases, but no specific syndrome could be recognized.

Hydrocephaly associated with Arnold-Chiari malformation takes part of the spina bifida spectrum: in this study, it was identified in 54\% (67/124) cases of spina bifida. Its frequency differed according to the level of the lesion, from $17 \%(2 / 12)$ if thoracolumbar, to $76 \%(28 / 37)$ if lumbar, and 80\% (37/46) if lumbosacral level.

Clubfoot, which represents a secondary deformation and not a true associated malformation, was recorded in $18 \%(22 / 124)$ of the cases, $17 \%$ of thoracolumbar $(2 / 12)$, $30 \%$ of lumbar $(11 / 37)$ and $20 \%$ of lumbosacral types (9/46).

\section{Time of Diagnosis (fig. 5)}

- Anencephaly: The sensitivity of ultrasound detection was 99\% (112/113) between 1995 and 2009, without statistically significant variation during the three periods 1995-1999, 2000-2004 and 2005-2009 (Fisher's exact test, $\mathrm{p}=1)$. The only case diagnosed at birth concerned a woman whom only one late ultrasound at 38 WA was considered as normal. The mean gestational age for ultrasound detection was 14.0 WA: it decreased over the three periods but not significantly (KruskalWallis test, $\mathrm{p}=0.10$ ).

- Cephalocele: The global sensitivity of prenatal diagnosis was $74 \%(26 / 35)$; it rose but not significantly throughout the whole period, from $67 \%$ between 1995 and 1999 to $75 \%$ between 2000 and 2004 and $89 \%$ between 2005 and 2009 (Cochran-Armitage exact trend test, $\mathrm{p}=0.26$ ). The mean gestational age for ultrasound detection was 16.2 WA, decreasing over the three periods, but not significantly (Kruskal-Wallis test, $\mathrm{p}=0.37$ ).

- Spina bifida: The sensitivity of prenatal diagnosis was $81 \%(100 / 124)$; it increased but not significantly throughout the whole period, from 75\% between 1995 and 1999 to $82 \%$ between 2000 and 2004 and $84 \%$ between 2005 and 2009 (Cochran-Armitage exact trend test, $\mathrm{p}=0.34)$. The mean gestational age for ultrasound detection was 20.9 WA and significantly decreased over the three periods (Kruskal-Wallis test, $\mathrm{p}=0.018)$.
10

Fetal Diagn Ther 2015;37:6-17 DOI: $10.1159 / 000362663$
Timbolschi et al. 


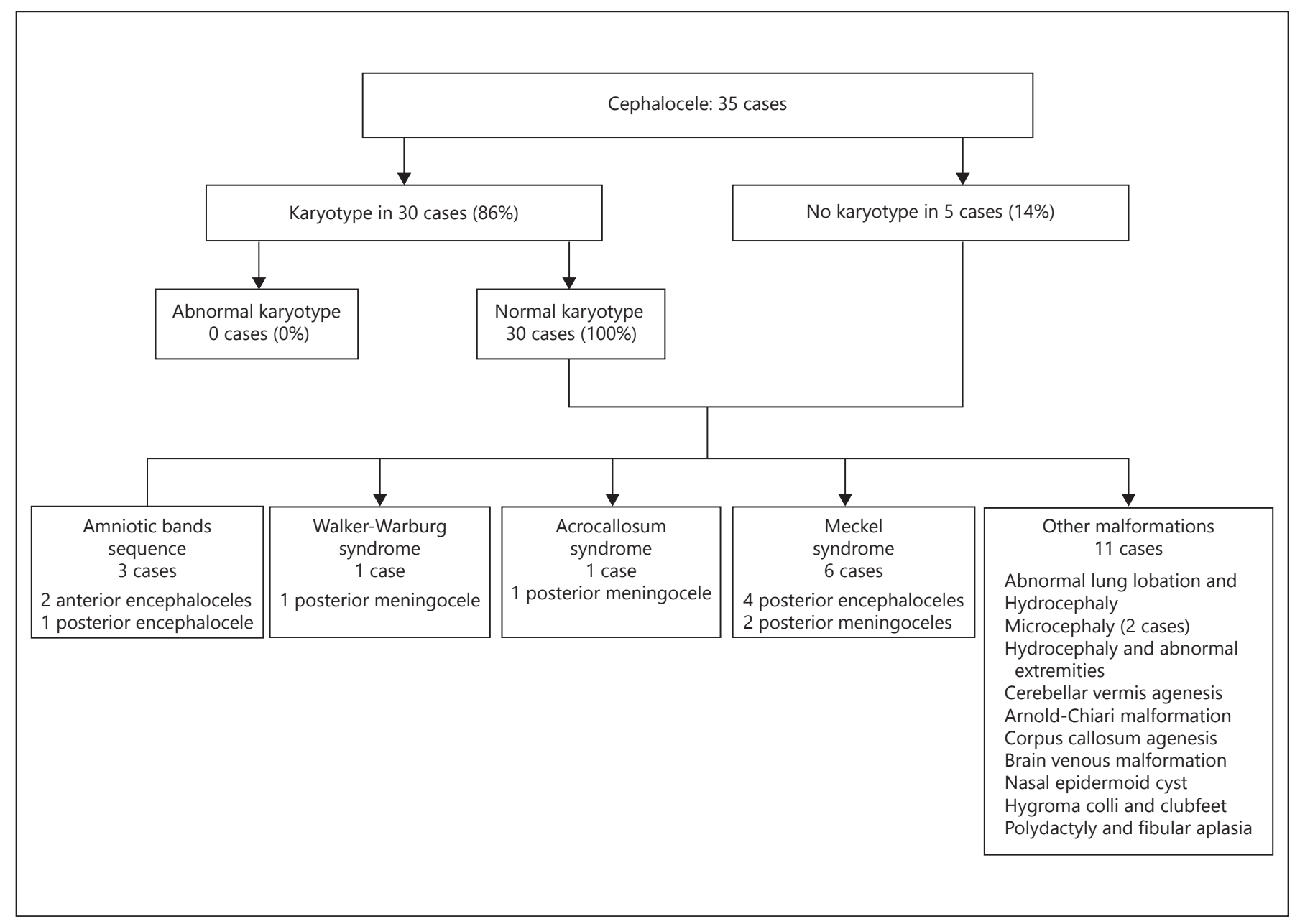

Fig. 3. Distribution and description of isolated and associated (syndromic or non-syndromic) cases with cephalocele.

The rates of prenatal diagnosis of each NTD significantly differed with a highest rate for anencephaly $\left(\chi^{2}\right.$ test, $p>0.0001)$. The prenatal diagnosis was predominantly performed during the first trimester of pregnancy for anencephaly (69.6\%) and during the second trimester for cephalocele (57.7\%) and spina bifida (81.0\%) (table 2)

Outcome of Pregnancy (fig. 6-8)

ToP was performed in 109 out of the 112 prenatally diagnosed cases (97\%) of anencephaly (mean gestational age of $15.0 \mathrm{WA}$ ), in 24 out of the 26 prenatally diagnosed cases (92\%) of cephalocele (mean gestational age of $17.3 \mathrm{WA}$ ) and in 97 out of the 100 prenatally diagnosed cases (97\%) of spina bifida (mean gestational age of $22.9 \mathrm{WA}$ ). There were no statistical differences concerning ToP rates according to NTD types (Fisher's exact test, $\mathrm{p}=0.37$ ).

\section{Autopsy}

An autopsy was performed in 103 cases of anencephaly (91\%), 26 cases of cephalocele (87\%), and 78 cases of spina bifida (77\%) and allowed to identify:

- The NTD itself for 2 isolated cases of spina bifida.

- The NTD and its etiological diagnosis for 1 meningocele with Walker-Warburg syndrome, 1 meningocele with amniotic bands, and 1 spina bifida with caudal regression sequence.

- The NTD and other anomalies for 3 cases of associated meningocele and 3 cases of spina bifida.

- Anomalies associated to the prenatally diagnosed NTD and leading to the etiological diagnosis for 9 cases of amniotic bands, 5 cases of Meckel syndrome and 1 case of acrocallosum syndrome.

- Ten cases of associated anomalies leading to exclude the diagnosis of an isolated NTD. 


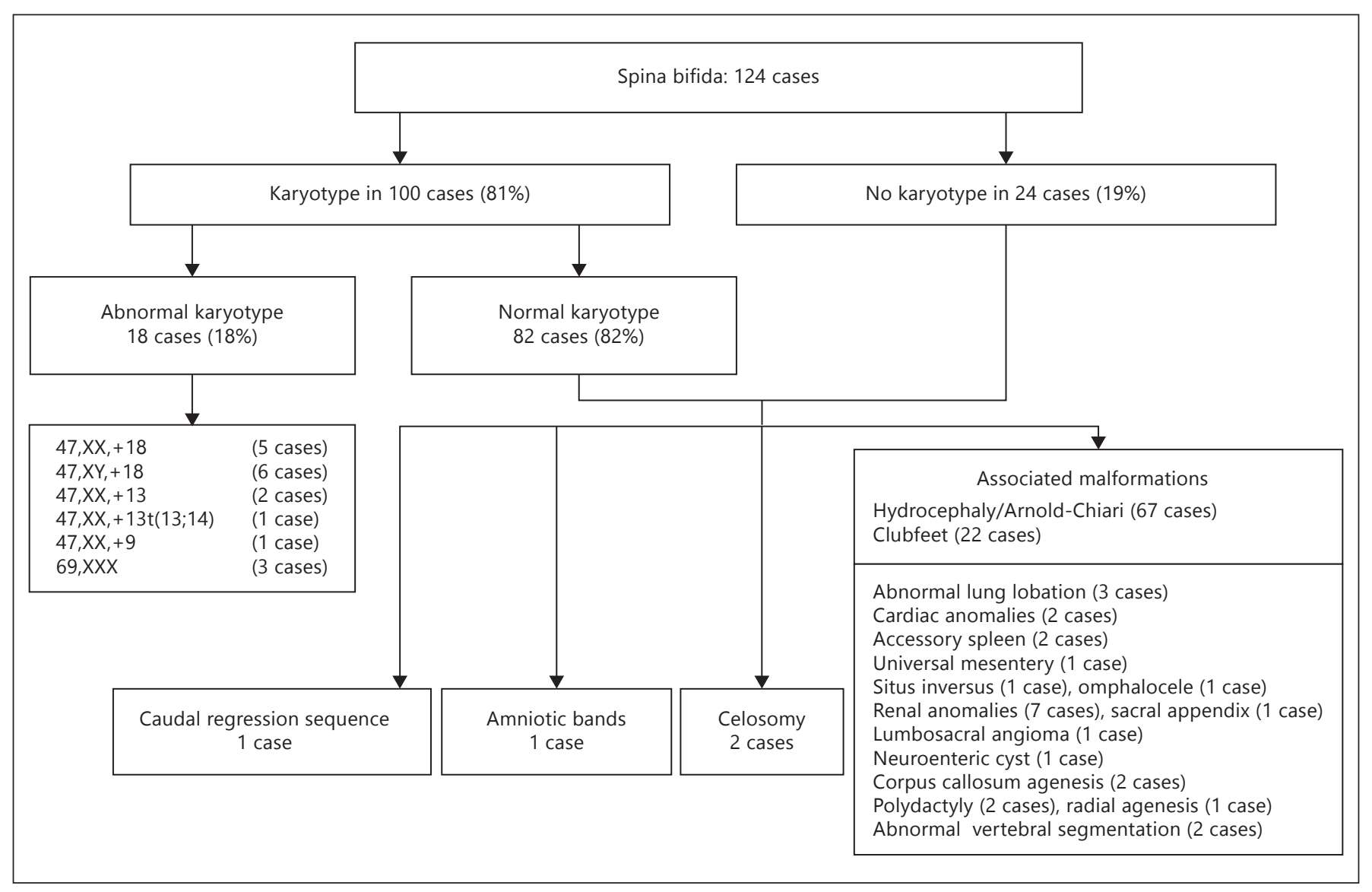

Fig. 4. Distribution and description of isolated and associated (syndromic or non-syndromic) cases with spina bifida.

Fig. 5. Percentage (upper figure) and age (lower figure) of ultrasound diagnosis for all NTDs and different types, between 1995-1999 (first columns), 2000-2004 (second columns) and 2005-2009 (third columns).

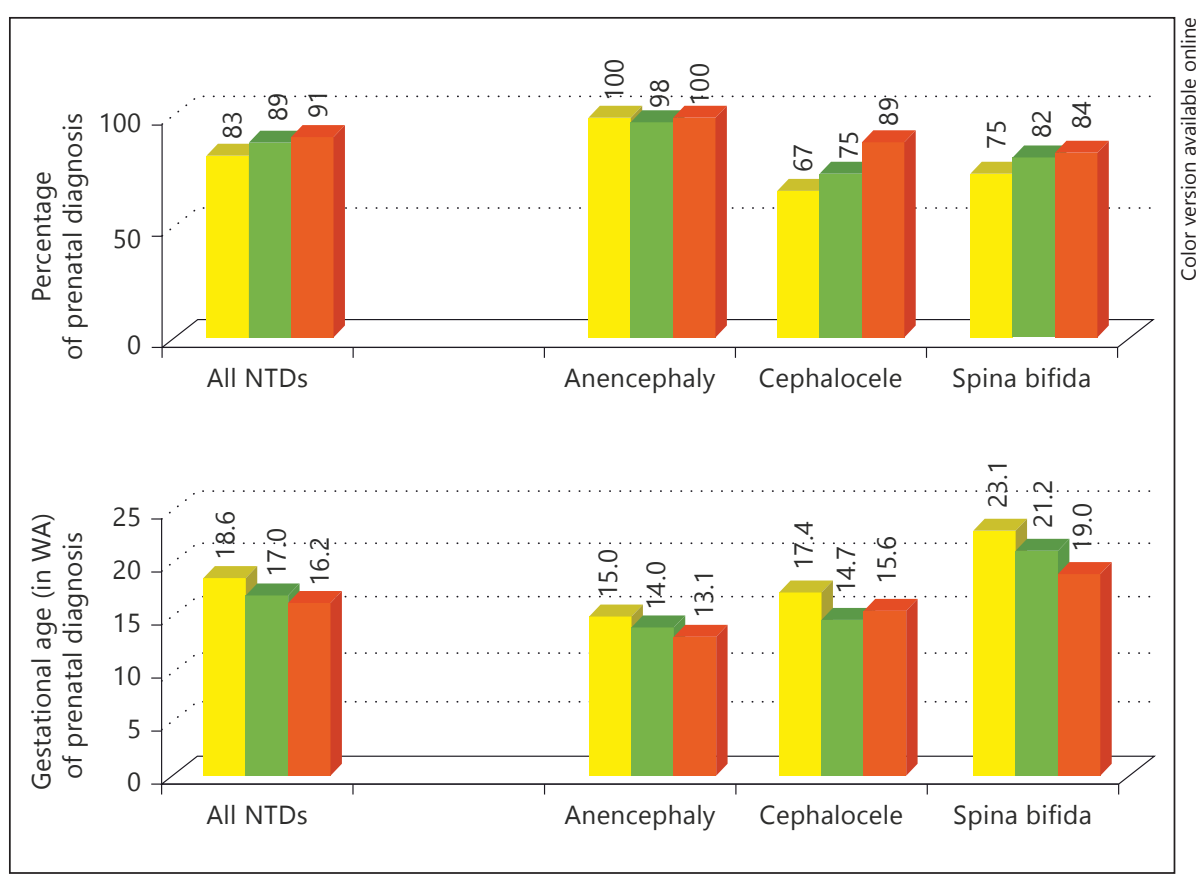




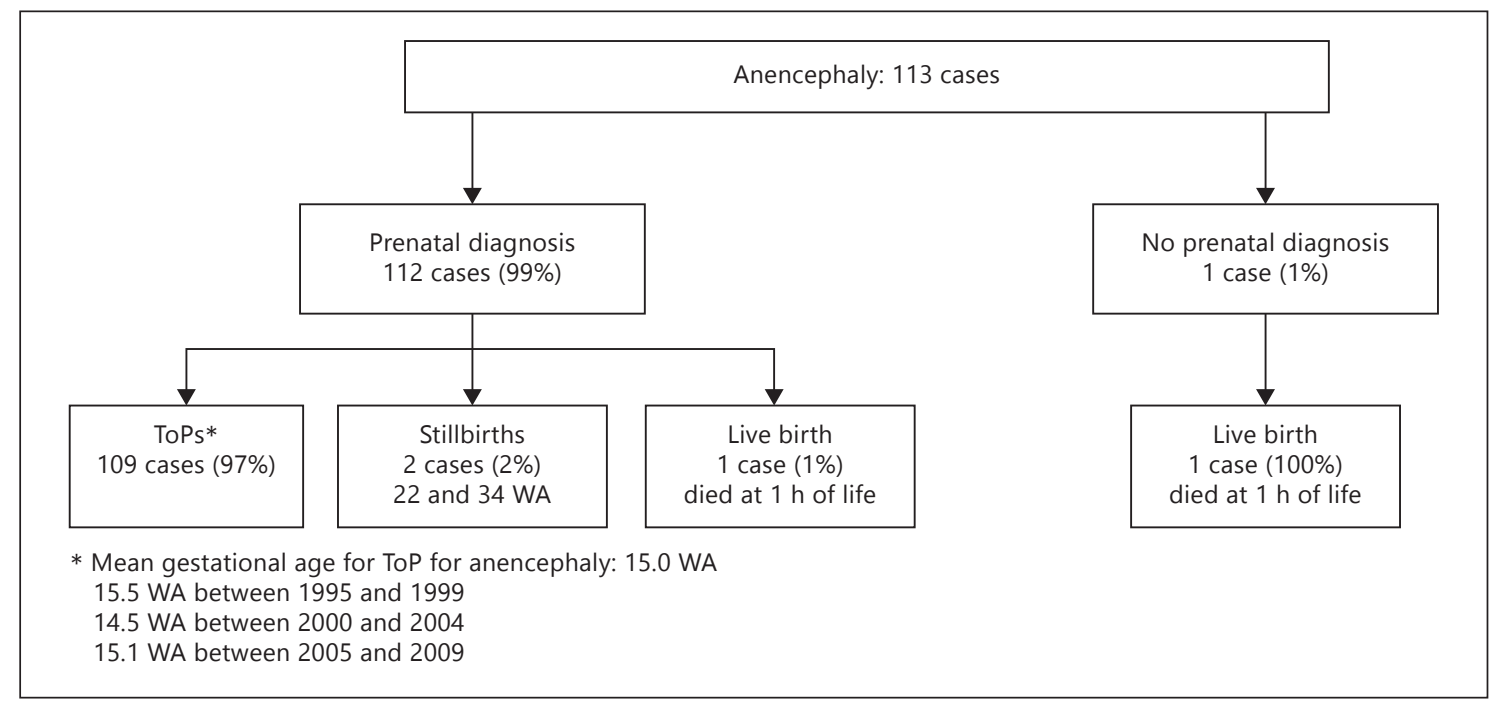

Fig. 6. Outcome of anencephaly.

Table 2. Detection rate of NTDs by ultrasound in the first, second and third trimesters of pregnancy

\begin{tabular}{|c|c|c|c|c|c|c|c|c|}
\hline \multirow[t]{3}{*}{ Trimesters } & \multicolumn{8}{|c|}{ Ultrasound detection } \\
\hline & \multicolumn{2}{|c|}{ anencephaly } & \multicolumn{2}{|c|}{ cephalocele } & \multicolumn{2}{|c|}{ spina bifida } & \multicolumn{2}{|l|}{ total } \\
\hline & $\mathrm{n}$ & $\%$ & $\mathrm{n}$ & $\%$ & $\mathrm{n}$ & $\%$ & $\mathrm{n}$ & $\%$ \\
\hline \multicolumn{9}{|c|}{ First trimester } \\
\hline 1-10 WA & 5 & 4.4 & 1 & 3.8 & 0 & 0.0 & 6 & 2.5 \\
\hline 11-14 WA & 73 & 65.2 & 10 & 38.5 & 10 & 10.0 & 93 & 39.1 \\
\hline \multicolumn{9}{|c|}{ Second trimester } \\
\hline 15-20 WA & 28 & 25.0 & 12 & 46.2 & 36 & 36.0 & 76 & 31.9 \\
\hline 21-28 WA & 4 & 3.6 & 3 & 11.5 & 45 & 45.0 & 52 & 21.9 \\
\hline \multicolumn{9}{|c|}{ Third trimester } \\
\hline 29-32 WA & 2 & 1.8 & 0 & 0.0 & 5 & 5.0 & 7 & 2.9 \\
\hline $33-42 \mathrm{WA}$ & 0 & 0.0 & 0 & 0.0 & 4 & 4.0 & 4 & 1.7 \\
\hline Total & 112 & & 26 & & 100 & & 238 & \\
\hline
\end{tabular}

\section{Discussion}

This population-based retrospective study constitutes the first recent study to focus on NTDs in France. Major findings are the determination of the prevalence of $14 / 10,000$ (95\% CI 13-16) and the high rate of prenatal diagnosis of $88 \%$ leading to a high global rate of ToP of $97 \%$.

\section{Prevalence}

If NTDs are among the most common congenital anomalies $[14,15]$, their prevalence is variable among different parts of the world depending on geographic region, seasons at conception, gender of the affected infant, ethnicity, socioeconomic status of parents, maternal age and parity $[16,17]$.

Our study showed a total NTD prevalence of $14 / 10,000$ [13-16], intermediate between the higher prevalence reported in North England (17.9/10,000) by Rankin et al. [18] in 2000 and the lower prevalence reported in Spain $(9.5 / 10,000)$ by Salvador et al. [19] in 2011. The distribution of each NTD malformation was similar to that reported in the two above-cited papers: $41 \%$ of anencephaly (versus 43 and $46 \%$, respectively), $13 \%$ of cephalocele (versus 6.5 and $10 \%$ ) and $46 \%$ of spina bifida (versus 51 and $44 \%$ ). 


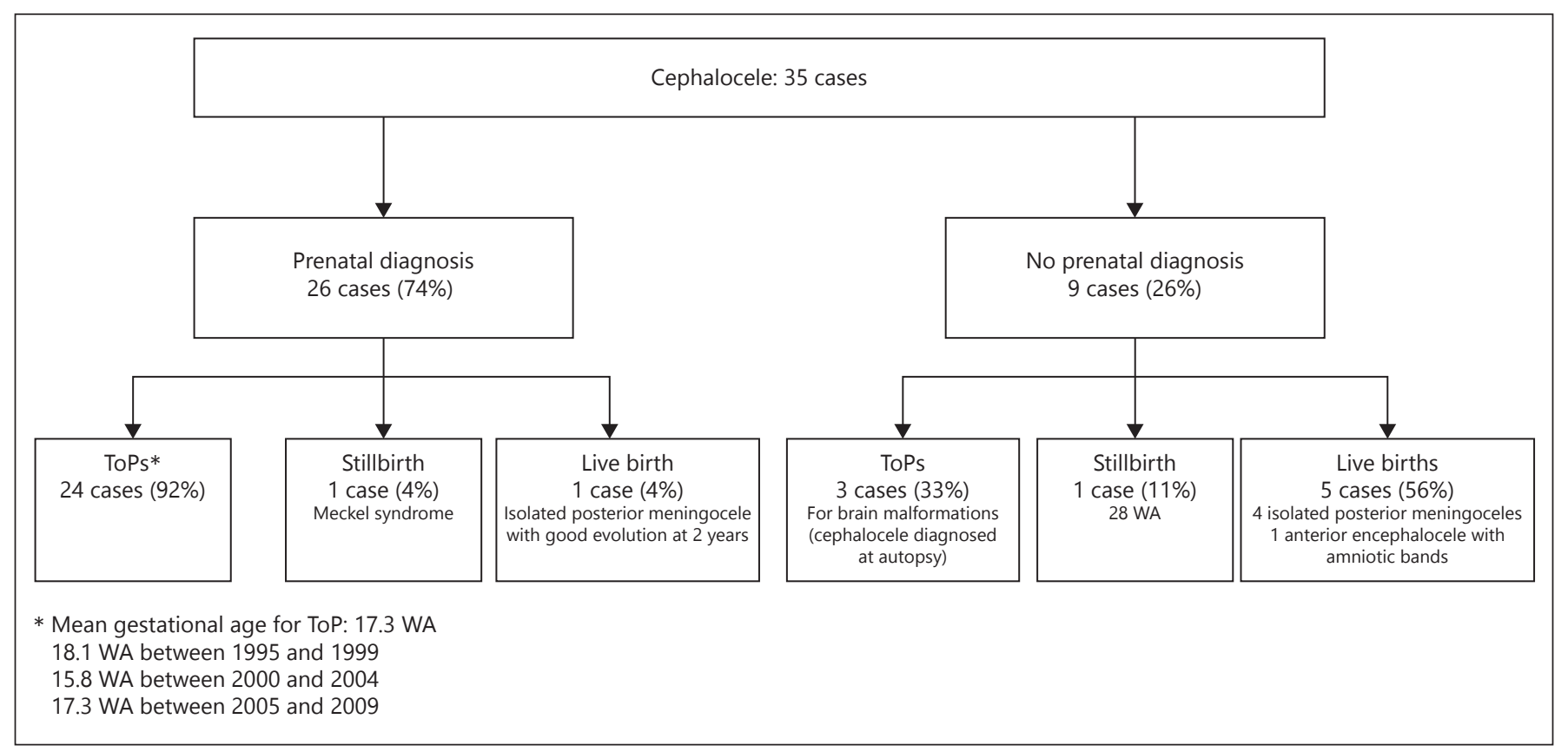

Fig. 7. Outcome of cephalocele.

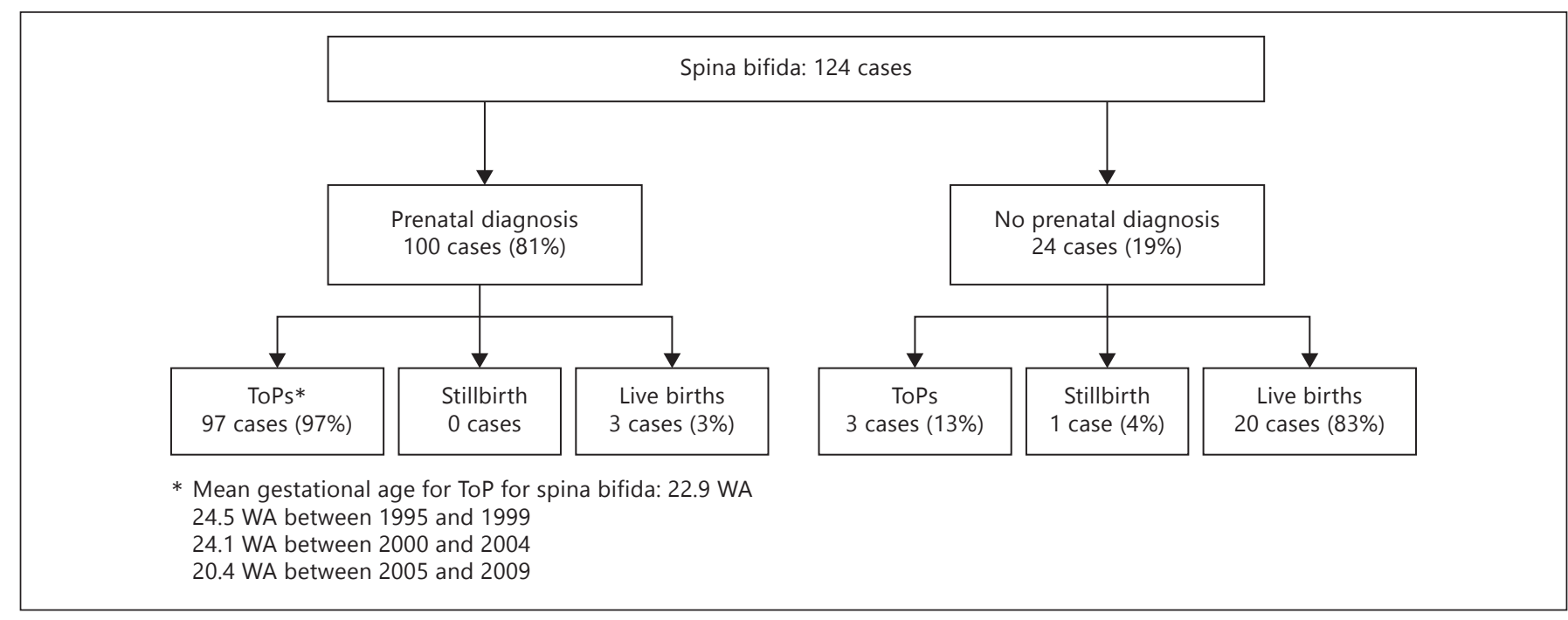

Fig. 8. Outcome of spina bifida.

Our study demonstrated no significant decrease in NTDs prevalence during the whole period which may ask the question about primary prevention with folic acid. In our French region, in addition to the lack of a fortification program, periconceptional supplementation is poorly adopted by women, accounting for about $10 \%$ in the 2000-2005 period [personal data]. This may be related to low awareness of the population, late prescription for unplanned pregnancies and low treatment compliance. Concerning this study, data concerning folic acid intake were very poor: appropriate folic acid intake was reported in only 6 women ( 2 with anencephaly and 4 with spina bifida) whereas late intake (after 6 WA) and unspecified intake were reported in 1 woman with anencephaly and 1 woman with spina bifida, respectively.

The incidence of isolated NTD among first- and second-degree relatives of affected infants appears to be sig- 
nificantly higher (about 2-5 times higher) than that reported in the general population [20]. In our study, after exclusion of syndromic cases, familial recurrence was present in 4 cases of anencephaly and 6 cases of spina bifida (respectively 4 and 6\% of the non-syndromic NTDs).

Twinning appears to be associated with a significant increase in NTD over the rest of the population [21]. Two twin pregnancies with anencephaly and 5 with spina bifida were recorded in this study. All were bichorial-biamniotic discordant pregnancies with only 1 affected fetus. All twin pregnancies (whatever the presence or not of malformations) are collected in our registry which enabled us to determine that spina bifida was 3 times more frequent in twin pregnancy than in single pregnancy whereas the proportions of anencephaly in the two groups were similar [personal data]. The hypotheses remain unclear: it has been suggested that supplemental folic acid might play some role in the occurrence of twin pregnancy. Nevertheless, there is no convincing evidence to support this hypothesis [22] and among our 5 cases with spina bifida, only 1 woman had taken periconceptional supplementation.

\section{Aneuploidies}

Association of NTDs with aneuploidy has been well documented in the literature [23-26]. Since NTDs usually occur as the result of multifactorial inheritance rather than secondary to a chromosomal disorder $[14,15]$, some investigators considered that routine prenatal chromosome analysis was not warranted, particularly if apparently isolated defects [27]. Furthermore, the likelihood of terminating such an affected pregnancy whatever the karyotype result may limit the clinical usefulness of prenatal chromosome analysis [28]. Conversely, other authors have argued that cytogenetic routine prenatal chromosome analysis is indicated in view of the high prevalence of chromosome abnormality and the importance of this information for genetic counseling [29-32]. In our study, a chromosome abnormality was identified in 27 cases (12\% of all karyotyped cases); these cases were associated with other malformations which were all prenatally diagnosed. The most frequent chromosome abnormality was trisomy $18(15 / 27,56 \%)$. Our results showed a slightly higher frequency of chromosome abnormalities than the $5-10 \%$ rate in other studies [31-33]. Moreover, the distribution of chromosomally abnormal cases varied depending on the type of fetal defect. In our study, $18 \%(18 / 100)$ of cases with spina bifida had chromosomal abnormality, which was clearly higher than the $8-10 \%$ reported in the above-cited papers [31-33] but in accordance with the $16-20 \%$ rates reported in two others
$[29,30]$. Chromosomal abnormality was found in $10 \%$ of anencephaly: this contrasted with the study of Sepulveda et al. [33] who reported only one chromosomal abnormality among 57 cases of anencephaly. Interestingly, no chromosomal abnormality was identified in our group of cephalocele, contrasting with a frequency about $15 \%$ in the literature [33-36]. We have no hypothesis to explain this difference: chromosomal investigations were performed in the majority of cephalocele (30/35) and in all cases including associated malformations.

Our results emphasize the importance to perform a systematic chromosomal analysis whatever the type of NTDs. In this study, only conventional cytogenetic analyses were performed. Recent studies using array comparative genomic hybridization have led to identify several copy number variations but these studies concerned isolated case reports only and no large series have been published until now [37-42].

\section{Prenatal Diagnosis}

Concerning prenatal diagnosis of all NTDs, an $88 \%$ detection rate was identified by routine ultrasound. While the prenatal detection rate has ranged from 79 to $100 \%$ during the last 20 years in studies performed in high-risk populations of North America and Europe [43-45], the rates in the general population like ours were somewhat lower, ranging from 62 to $86 \%$ [9, 18, 46-48]. Our $88 \%$ detection rate was one of the highest observed in the general population, but lower than the $94 \%$ reported in the study of Salvador et al. [19] performed in Spain from 1992 to 2006. In our study, although increasing detection among the 15-year period would be expected, as observed for other malformations, stable rates were observed. Considering each NTD type, our $99 \%$ sensitivity of prenatal diagnosis of anencephaly was in the upper range compared to the $87-100 \%$ results in the literature $[49,50]$. The sensitivity of prenatal detection of cephalocele was $74 \%$ in our series, which was difficult to compare with the literature due to the large variability with rates ranging from 8 in Nigeria to $92 \%$ in California and $100 \%$ in Spain [19, $42,51]$. Focusing on spina bifida, our results were also in the upper range (81\%) compared to reported prenatal detection rates ranging from 38 to $84 \%[11,19]$.

Considering the time of prenatal diagnosis, we found a decrease of the average age of prenatal diagnosis for all NTDs (but statistical significance was demonstrated only for spina bifida). In our cohort, anencephaly was mostly detected in the first trimester of pregnancy (69.6\%) which was similar to the rate of $60 \%$ reported by Salvador et al. [19] between 1997 and 2006. Our results confirmed that 
spina bifida remained to be predominantly diagnosed during the second trimester ( 81.0 vs. $72.7 \%$ for Salvador et al. [19]). These authors found an $83.3 \%$ rate of firsttrimester diagnosis of cephalocele whereas it was only of $42.3 \%$ in our study.

Initially, NTD screening programs were based on maternal $\alpha$-fetoprotein (AFP) dosage determined during the second trimester. From the 1990s, AFP was frequently used considering the diffusion of Down's syndrome screening. In France, as the prenatal screening includes three ultrasounds at 12, 22 and $32 \mathrm{WA}$, the interest of maternal AFP was to alert of a NTD at about $16 \mathrm{WA}$, before the 22 WA ultrasound; in our study, among the 100 prenatally diagnosed spina bifida, we could identify 27 cases for whom abnormal AFP constituted the first indicator of NTD leading to advance the date of ultrasound. Nowadays, AFP is progressively being abandoned considering the migration to first-trimester combined screening and it will be interesting to study the impact on NTD prenatal diagnosis in the future [52].

In our study, the global rate of ToPs after prenatal diagnosis was 97\% (230/238). This was similar to the result of $98.3 \%$ in the recent Chinese study performed by Lu et al. [53] in 2011 but higher than the average rate (88\%) for 12 European countries (including ours) in 2008 [7]. The ToP rates were almost similar between the different NTD types: $97 \%$ for anencephaly, $92 \%$ for cephalocele and $97 \%$ for spina bifida. These rates are similar to those reported by Lu et al. [53] (100\% for anencephaly, 95.7\% for cephalocele and $97.2 \%$ for spina bifida) but higher than those reported in the systematic review of Mansfield et al. [54] (84\% for anencephaly, $64 \%$ for spina bifida) and the study reported by Garne et al. [10] (90\% for anencephaly, 84\% for cephalocele and $78 \%$ for spina bifida). Many factors, including prenatal screening policies, burden of treatment cost, organization and culture, are susceptible to affect the ToP rates. French law on bioethics (adopted in 1994 and revised in 2004) states that 'termination of preg- nancy for fetal anomaly is legally justified if the fetus suffers from a particularly severe disorder, recognized as incurable at the time of diagnosis'. In France, there is no upper legal gestational limit for ToP due to fetal anomalies. This could explain, at least in part, the higher ToP rate for spina bifida, preferentially diagnosed between 21 and 28 WA. Recent developments of prenatal repair of myelomeningocele are susceptible to influence practices in the future [55].

In conclusion, this population-based study provides recent and detailed data about NTDs in a French region, between 1995 and 2009. The most important information concerns the evolution of the prevalence and the efficiency of prenatal diagnosis. The prevalence of NTDs remains stable during the period considered but is still high, which calls into question the efficiency of the primary prevention by folic acid supplementation. The prenatal diagnosis of all NTDs is clearly effective, with an $88 \%$ detection rate population, and a slight decrease of the average gestational age at diagnosis over time. Comparative studies with other French regions could be very interesting in the future. Indeed, significant variations of NTDs prevalence between French regions have been demonstrated [13] (18/10,000 on Reunion Island vs. $13 / 10,000$ in Paris) and it would be relevant to investigate environmental or genetic factors which could explain these differences.

\section{Acknowledgements}

The authors thank all health professionals, the patients and their families for their collaboration in this study and also thank InVS (Institut de Veille Sanitaire), INSERM and CREGEMES (Centre Régional de Génétique Médicale de Strasbourg) for their financial support.

\section{Disclosure Statement}

The authors have no conflicts of interest to disclose.

\section{References}

1 Campbell LR, Dayton DH, Sohal GS: Studies on the etiology of neural tube defects. Teratology 1986;34:171-187.

2 Dias MS, Partington M: Embryology of myelomeningocele and anencephaly. Neurosurg Focus 2004;16:E1.

3 Padmanabhan R: Etiology, pathogenesis and prevention of neural tube defects. Congenit Anom (Kyoto) 2006;46:55-67.
4 Volcik KA, Blanton SH, Kruzel MD, et al: Testing for genetic associations in a spina bifida population: analysis of the HOX gene family and human candidate gene regions implicated by mouse models of neural tube defects. Am J Med Genet 2002;110:203207.

5 Frey L, Hauser WA: Epidemiology of neural tube defects. Epilepsia 2003;44:4-13.
6 MCR Vitamin Study Research Group: Prevention of neural tube defects: results of the MCR Vitamin Study. Lancet 1991;338:131137.

7 Czeizel AE, Dudas I: Prevention of the first occurrence of neural-tube defects by periconceptional vitamin supplementation. $\mathrm{N}$ Engl J Med 1992;327:1832-1835.
16

Fetal Diagn Ther 2015;37:6-17 DOI: $10.1159 / 000362663$
Timbolschi et al. 
8 Boyd PA, Wellesley DG, De Walle HE, et al: Evaluation of the prenatal diagnosis of neural tube defects by fetal ultrasonographic examination in different centres across Europe. J Med Screen 2000;7:169-174.

9 Stoll C, Alembik Y, Dott B, Roth MP: Impact of prenatal diagnosis on livebirth prevalence of children with congenital anomalies. Ann Genet 2002;45:115-121.

10 Garne E, Loane M, Dolk H, et al: Prenatal diagnosis of severe structural malformations in Europe. Ultrasound Obstet Gynecol 2005;25:6-11.

11 Boyd PA, De Vigan C, Khoshnood B, et al: Survey of prenatal screening policies in Europe for structural malformations and chromosome anomalies, and their impact on detection and termination rates for neural tube defects and Down's syndrome. BJOG 2008;115:689-696.

12 Khoshnood B, Greenless R, Loane M, Dolk H: Paper 2: EUROCAT Public Health indicators for congenital anomalies in Europe. Birth Defects Res 2011;91:S16-S22.

13 Greenlees R, Neville A, Addor MC, et al: Paper 6: EUROCAT member registries: organization and activities. Birth defects Res A Clin Mol Teratol 2011;91(suppl 1):S51-S100.

14 Main DM, Mennuti MT: Neural tube defects: issues in prenatal diagnosis and counseling. Obstet Gynecol 1986;67:1-16.

$\checkmark 15$ Botto LD, Moore CA, Khoury MJ, et al: Neural-tube defects. N Engl J Med 1999;341: 1509-1519.

-16 Laurence KM, Carter CO, David PA: Major central nervous study system and malformations in South Wales. II. Pregnancy factors, seasonal variation, and social class effects. $\mathrm{Br}$ J Prev Soc Med 1968;22:212-222.

17 Xiao KZ, Zhang ZY, Su YM, et al: Central nervous system congenital malformations, especially neural tube defects in 29 provinces, metropolitan cities and autonomous regions of China: Chinese birth defects monitoring program. Int J Epidemiol 1990;19:978-982.

18 Rankin J, Glinianaia S, Brown R, et al: The changing prevalence of neural tube defects: a population-based study in the North of England, 1984-96. Paediatr Perinat Epidemiol 2000;14:104-110.

-19 Salvador J, Arigitta M, Carreras E, Lladonosa A, Borrell A: Evolution of prenatal detection of neural tube defects in the pregnant population of the city of Barcelona from 1992 to 2006. Prenat Diagn 2011;31:1184-1188.

20 Sebold CD, Melvin EC, Siegel D, et al: NTD Collaborative Group Recurrence risks for neural tube defects in siblings of patients with lipomyelomeningocele. Genet Med 2005;7:64-67.

-21 Windham GC, Sever LE: Neural tube defects among twin births. Am J Med Genet 1982;34: 988-998.

22 Li Z, Gindler J, Wang H, et al: Folic acid supplements during early pregnancy and likelihood of multiple births: a population-based cohort study. Lancet 2003;361:380-384.

23 Flannery DB, Kahler SG: Neural tube defects in trisomy 18. Prenat Diagn 1986;6:97-99.
4 Moore CA, Harman JP, Padilla LM, et al: Neural tube defects and omphalocele in trisomy 18. Clin Genet 1988;34:98-103.

25 Rodriguez JL, Garcia M, Morales C, et al: Trisomy 13 syndrome and neural tube defects. Am J Med Genet 1990;36:513-516.

26 Seller MJ: Neural tube defects, chromosome abnormalities and multiple closure sites for the human neural tube. Clin Dysmorphol 1995;4:202-207.

27 Nicolaides KH, Snijders RJ, Gosden CM, et al: Ultrasonographically detectable markers of fetal chromosomal abnormalities. Lancet 1922;340:704-707.

28 Sturgiss S, Robson S: Prognosis for fetuses with antenatally detected myelomeningocele. Fetal Mater Med Rev 1995;7:235-249.

29 Babcook CJ, Golstein RB, Filly RA: Prenatally detected fetal myelomenongocele: is karyotype analysis warranted? Radiology 1995;94: 491-494.

30 Harmon JP, Hiett AK, Palmer CG, Golichowski AM: Prenatal ultrasound detection of isolated neural tube defects: is cytogenetic evaluation warranted? Obstet Gynecol 1995;86:595-599.

31 Hume RF, Drugan A, Reichler A, et al: Aneuploidy among prenatally detected neural tube defects. Am J Med Genet 1996;61:171-173.

32 Kennedy D, Chitayat D, Winsor EJT, et al: Prenatally diagnosed neural tube defects: ultrasound, chromosome, and autopsy or postnatal findings in 212 cases. Am J Med Genet 1998;77:317-321.

33 Sepulveda W, Corral E, Ayala C, et al: Chromosomal abnormalities in fetuses with open neural tube defects: prenatal identification with ultrasound. Ultrasound Obstet Gynecol 2004;23:352-356.

34 Goldstein RB, LaPidus AS, Filly RA: Fetal cephaloceles: diagnosis with ultrasound. Radiology 1991;180:803-808.

35 Winniger SJ, Donnenfeld AE: Syndromes identified in fetuses with prenatal diagnosed cephaloceles. Prenat Diagn 1994;14:839-843. 36 Budorick NE, Pretorius DH, McGahan JP, et al: Cephalocele detection in utero: sonographic and clinical features. Ultrasound $\mathrm{Ob}$ stet Gynecol 1995;5:77-85.

- 37 Ballarati L, Rossi E, Bonaiti MT, et al: 13q deletion and central nervous system anomalies: further insights from karyotype-phenotype analyses of 14 patients. J Med Genet 2007;44:e60.

- 38 Ben-Abdallah-Bouhjar I, Mougou-Zerelli S, Hannachi H, et al: Phenotype and micro-array characterization of duplication 11q22.1q25 and review of the literature. Gene 2013; 519:135-141.

39 Burche A, Klopocki E, Ullmann R, et al: A cryptic unbalanced translocation $\mathrm{t}(2 ; 9)$ (p25.2;q34.3) causes the phenotype of 9q subtelomeric deletion syndrome and additional exophthalmos and joint contractures. Eur J Med Genet 2008;51:615-621.

40 Chen CP, Su YN, Tsai FJ, et al: Partial monosomy $13 q(13 q 21.32 \rightarrow q$ ter $)$ and partial trisomy $8 p$ $(8 \mathrm{p} 1 \rightarrow$ pter $)$ presenting with anencephaly and increased nuchal translucency: array compara- tive genomic hybridization characterization. Taiwan J Obstet Gynecol 2011;50:205-211.

41 Gustavsson P, Schoumans J, Staaf J, et al: Duplication 16q12.1-q22.1 characterized by array CGH in a girl with spina bifida. Eur J Med Genet 2007;50:237-241.

42 Kirchhoff M, Bisgaard AM, Stoeva R, et al: Phenotype and $244 \mathrm{k}$ array-CGH characterization of chromosome $13 \mathrm{q}$ deletions: an update of the phenotypic map of 13q21.1 $\rightarrow$ qter. Am J Med Genet A 2009;149A:894-905.

43 Romero R, Mathisen JM, Ghidini A, et al: Accuracy of ultrasound in the prenatal diagnosis of spinal anomalies. Am J Perinatol 1989;6: $320-323$.

44 Jorgensen FS, Valentin L, Salvesen KA, et al Multiscan - a Scandinavian multicenter second-trimester obstetric ultrasound and serum screening study. Acta Obstet Gynecol Scand 1999;78:501-510.

45 Dashe JS, Twickler DM, Santos-Ramos R, et al: Alpha-fetoprotein detection of neural tube defects and the impact of standard ultrasound. Am J Obstet Gynecol 2006;195:1623-1628.

-46 Forrester MB, Merz RD: Prenatal diagnosis and elective termination of neural tube defects in Hawaii, 1986-1997. Fetal Diagn Ther 2000;15:146-151.

47 Norem CT, Schoen EJ, Walton DL, et al: Routine ultrasonography compared with maternal serum $\alpha$-fetoprotein for neural tube defect screening. Obstet Gynecol 2005;106:747-752.

48 Van Allen MI, Boyle E, Thiessen P, et al: The impact of prenatal diagnosis on neural tube defect pregancy versus birth incidence in British Columbia. J Appl Genet 2006;47:151-158.

49 Johnson SP, Sebire NJ, Snijders RJ, et al: Ultrasound screening for anencephaly at 10-14 weeks of gestation. Ultrasound Obstet Gynecol 1997;9:14-16.

50 Cameron M, Moran P: Prenatal screening and diagnosis of neural tube defects. Prenat Diagn 2009;29:402-411.

51 Adetiloye VA, Dare FO, Oyelami OA: A tenyear review of encephalocele in a teaching hospital. Int J Gynaecol Obstet 1993;41:241-249.

52 Borrel A, Casals E, Fortuny A, et al: First-trimester screening for trisomy 21 combining biochemistry and ultrasound at individually optimal gestational ages. An interventional study. Prenat Diagn 2004;24:541-545.

53 Lu QB, Wang ZP, Gong R, et al: Investigation of ultrasound screening efficiency for neural tube defects during pregnancy in rural areas of China. Public Health 2011;125:639-644.

54 Mansfield C, Hopfer S, Marteau TM: Termination rates after prenatal diagnosis of Down syndrome, spina bifida, anencephaly, and Turner and Klinefelter syndromes: a systematic literature review. European Concerted Action: DADA (Decision-making After the Diagnosis of a fetal Abnormality). Prenat Diagn 1999;19:808-812.

55 Adzick NS, Thom EA, Spong CY, et al: A randomized trial of prenatal versus postnatal repair of myelomeningocele. N Engl J Med 2011;364:993-1004. 